\title{
Open
}

\section{Diagnosis and treatment of tyrosinemia type I: a US and Canadian consensus group review and recommendations}

\author{
Jeffrey M. Chinsky, MD, $\mathrm{PhD}^{1}$, Rani Singh, $\mathrm{PhD}, \mathrm{RD}^{2}$, Can Ficicioglu, $\mathrm{MD}, \mathrm{PhD}^{3}$, \\ Clara D.M. van Karnebeek, MD, $\mathrm{PhD}^{4}$, Markus Grompe, $\mathrm{MD}^{5}$, Grant Mitchell, $\mathrm{MD}^{6}$, \\ Susan E. Waisbren, $\mathrm{PhD}^{7}$, Muge Gucsavas-Calikoglu, MD ${ }^{8}$, Melissa P. Wasserstein, MD ${ }^{9}$, \\ Katie Coakley, PhD, RD ${ }^{10}$ and C. Ronald Scott, MD ${ }^{11}$
}

\begin{abstract}
Tyrosinemia type I (hepatorenal tyrosinemia, HT-1) is an autosomal recessive condition resulting in hepatic failure with comorbidities involving the renal and neurologic systems and long term risks for hepatocellular carcinoma. An effective medical treatment with 2-[2-nitro-4-trifluoromethylbenzoyl]-1,3-cyclohexanedione (NTBC) exists but requires early identification of affected children for optimal long-term results. Newborn screening (NBS) utilizing blood succinylacetone as the NBS marker is superior to observing tyrosine levels as a way of identifying neonates with HT-1. If identified early and treated appropriately, the majority of affected infants can remain asymptomatic. A clinical management scheme is needed for infants with HT-1 identified by NBS or clinical symptoms. To this end, a group of 11 clinical practitioners, including eight biochemical genetics physicians, two metabolic dietitian nutritionists, and a clinical psychologist, from the United States and Canada, with experience in providing care for patients
\end{abstract}

with HT-1, initiated an evidence- and consensus-based process to establish uniform recommendations for identification and treatment of HT-1. Recommendations were developed from a literature review, practitioner management survey, and nominal group process involving two face-to-face meetings. There was strong consensus in favor of NBS for HT-1, using blood succinylacetone as a marker, followed by diagnostic confirmation and early treatment with NTBC and diet. Consensus recommendations for both immediate and long-term clinical follow-up of positive diagnoses via both newborn screening and clinical symptomatic presentation are provided.

Genet Med advance online publication 3 August 2017

Key Words: hepatocellular carcinoma; tyrosinemia; newborn screening; nitisinone; NTBC

\section{INTRODUCTION}

Tyrosinemia type I (hepatorenal tyrosinemia, HT-1) is an autosomal recessive condition (OMIM 276700) resulting in hepatic failure with comorbidities involving the renal and neurologic systems (for a comprehensive review, see Mitchell et al. ${ }^{1}$. Clinical symptoms typically begin before 2 years of age, with the majority of children presenting before the age of 6 months with evidence of acute liver failure and renal dysfunction. Neurologic crises, manifesting as painful episodes affecting extremity and/or abdominal function, accompanied by hypertension and hyponatremia, may present at any time and may result in respiratory failure and death. ${ }^{2}$ A few affected children may present over the age of 2 years with isolated coagulopathy or other signs of liver dysfunction, renal tubular disease, hypophosphatemic rickets, and failure to thrive. All children with HT-1 are at high risk for hepato- cellular carcinoma (HCC) and this also may be the first recognized clinical event. ${ }^{3}$ Survivors of these devastating complications in the past developed hepatomas that often transitioned to HCC, with lifetime frequencies as high as $37 \%{ }^{4-7}$ An effective medical treatment with 2-[2-nitro4-trifluoromethylbenzoyl]-1,3-cyclohexanedione (NTBC, nitisinone) exists but requires early identification of affected children for optimal long-term results. Initial efforts at newborn screening (NBS) to detect presymptomatic infants with HT-1 by measuring tyrosine levels identified some, but not all, affected children. Recently introduced, the use of blood succinylacetone (SA) as the NBS marker is predicted to identify all infants affected with HT- $1 .{ }^{8}$ If correctly identified and appropriately medically managed, the majority, if not all, of these infants with HT-1 can anticipate a life free of hepatic or renal disease.

\footnotetext{
${ }^{1}$ Department of Pediatrics, Johns Hopkins University School of Medicine, Baltimore, Maryland, USA; ${ }^{2}$ Department of Human Genetics and Pediatrics, Emory University School of Medicine, Atlanta, Georgia, USA; ${ }^{3}$ The Children's Hospital of Philadelphia, Division of Human Genetics and Metabolism, Perelman School of Medicine at The University of Pennsylvania, Philadelphia, Pennsylvania, USA; ${ }^{4}$ Department of Pediatrics, Centre for Molecular Medicine and Therapeutics, University of British Columbia, Vancouver, CA and Departments of Pediatrics and Clinical Genetics, Academic Medical Centre, University of Amsterdam, Amsterdam, Netherlands; ${ }^{5}$ Department of Pediatrics, Pape Family Pediatric Research Institute, Oregon Health and Science University, Portland, Oregon, USA; ${ }^{6} \mathrm{CHU}$ Sainte-Justine and Université de Montréal, Montreal, Quebec, Canada; ${ }^{7}$ Metabolism Program, Boston Children's Hospital, Boston, Massachusetts, USA; ${ }^{8}$ Department of Pediatrics, Division of Genetics and Metabolism, University of North Carolina, Chapel Hill, North Carolina, USA; ${ }^{9}$ The Children's Hospital at Montefiore, Albert Einstein College of Medicine, Bronx, New York, USA; ${ }^{10}$ Department of Human Genetics, Emory University School of Medicine, Atlanta, Georgia, USA; ${ }^{11}$ Division of Genetic Medicine, Department of Pediatrics, University of Washington School of Medicine, Seattle, Washington, USA. Correspondence: Jeffrey M. Chinsky (jchinsky1@gmail.com)
} 
An appropriate management scheme is clearly needed for infants with HT-1 identified by NBS or following presentation with clinical symptoms. Prior reviews highlight a heterogeneity of approaches to treatment and were written primarily based on European clinical practices where there is no universal NBS for presymptomatic HT-1. ${ }^{9-11}$ To this end, a group of 11 metabolic physicians, registered dietitian nutritionists, and psychologist from the United States and Canada with experience in providing care for patients with HT-1 initiated a consensus-based process to establish uniform recommendations for identification and treatment of affected children. Using results from a literature review, a metabolic practitioners management survey, and a nominal group process, recommendations were developed and are summarized in this report.

\section{METHODOLOGY}

This review and set of recommendations reflect the consensus opinions of a group of US and Canadian professionals comprising metabolic physicians, a psychologist, and a dietitian nutritionist, whose collective experience either directly or indirectly involves over 100 patients with HT-1. These clinicians, experienced in the treatment of HT-1, met twice in face-to-face meetings to review the HT-1 literature, summarize survey results, and vote on the recommendations (nominal group approach). Design for the overall consensus process was based on review of several published consensus approaches as well as recent methods used for similarly rare inborn errors of metabolism. ${ }^{12-15}$

A comprehensive review of the literature (including animal studies) was conducted in August 2015 using PubMed, Embase, and BIOSIS databases, searching for English language articles with no year restrictions, using defined search strategies based on input from five of the cited group members with experience of treating multiple patients with HT-1. ${ }^{12}$ Literature search results were sent to all invited members of the planned consensus group prior to the first meeting. At least two participants were assigned to each subsection of HT-1 topics and were asked to fully review the literature results, prepare a presentation for the group, and suggest recommendations.

A project consultant facilitated both nominal group meetings. The first group meeting was convened for one and one half days to discuss the literature search results, to present and discuss the comprehensive reviews of the assigned subsections, and to develop a clinical management survey to evaluate any variation in clinical practice between metabolic centers and/or individual practitioners. The survey was subsequently sent to metabolic physicians and nutritionists in Canada and the United States. The survey was in the field for approximately 6 weeks, and 49 responses were received (Supplementary Appendixes 1 and 2 online).

After the survey results were collected, a second nominal group meeting was held in January 2016. Based on the literature review, the survey results, and the individual clinical experiences of participants, the recommendations were proposed, refined, and discussed, with AGREE II criteria as a guide. ${ }^{16}$ Subsequently, recommendations were voted on and scored, with only recommendations reaching a level of agreement of $70 \%$ (strongly agree or agree) included in the present article. Group considerations, comments, and selected literature references relevant to each recommendation are presented in the immediate surrounding text. However, with no prospective randomized controlled trials (RCTs) for either therapies or approaches (NBS programs) and very low numbers of affected individuals, assigning letter grades of literature evidence quality is difficult. This problem has been addressed by stressing the need for a hybrid approach blending evidence- and consensus-based processes for recommendations regarding inborn errors of metabolism. ${ }^{17}$ Compounding the issue is the fact that various professional organizations and grading references (the American Academy of Pediatrics, American Family Practice, Scottish Intercollegiate Guidelines Network, and many others) have different letter assignments and cutoffs for the use of non-RCT-containing literature, creating confusion about the meaning of an $\mathrm{A}, \mathrm{B}$, or $\mathrm{C}$ to denote the quality of literature used for evidence. ${ }^{18,19}$

We assigned letter grades to each of our recommendations to convey our opinion of the literature's evidential support for these recommendations. The following letter grades are based on the evidence quality criteria proposed by the American Academy of Pediatrics: A = well-designed RCTs or diagnostic studies on relevant populations; $\mathrm{B}=$ RCTs or diagnostic studies with minor limitations and overwhelmingly consistent evidence from observational studies; $C=$ observational studies (case control and cohort design); $\mathrm{D}=$ expert opinion, case reports, reasoning from first principles; $\mathrm{X}=$ exceptional situations where validating studies cannot be performed and there is a clear preponderance of benefit or harm. ${ }^{20}$ Using this system, a grade of B could be applied to the few recommendations that were supported by three or more prospective observational studies with clear benefit. A grade of $\mathrm{C}$ was assigned if the issue was based on a relatively strong observational study or fewer than three studies of any design. Recommendations based solely on case reports (or weaker and/or smaller observational case series, as well as expert opinion) were assigned a grade of $\mathrm{D}$. When possible, evidence published in 2016 during the writing of this paper was included.

\section{PATHOPHYSIOLOGY OF HT-1}

In 1977, fumarylacetoacetate hydrolase (FAH) was identified as the deficient enzyme responsible for HT-1 (Figure 1). This enzyme is the terminal step in the tyrosine catabolic pathway. ${ }^{21}$ HT-1 is differentiated from another condition with dramatically elevated blood tyrosine levels that produces a severe dermatologic and ophthalmologic condition (tyrosinemia type II). In HT-1 patients, dietary restriction of phenylalanine and tyrosine, even if begun within the first month of life, did not eliminate the development of hepatic, renal, or neurological complications. Orthotopic liver transplantation became the therapeutic option for patients who 


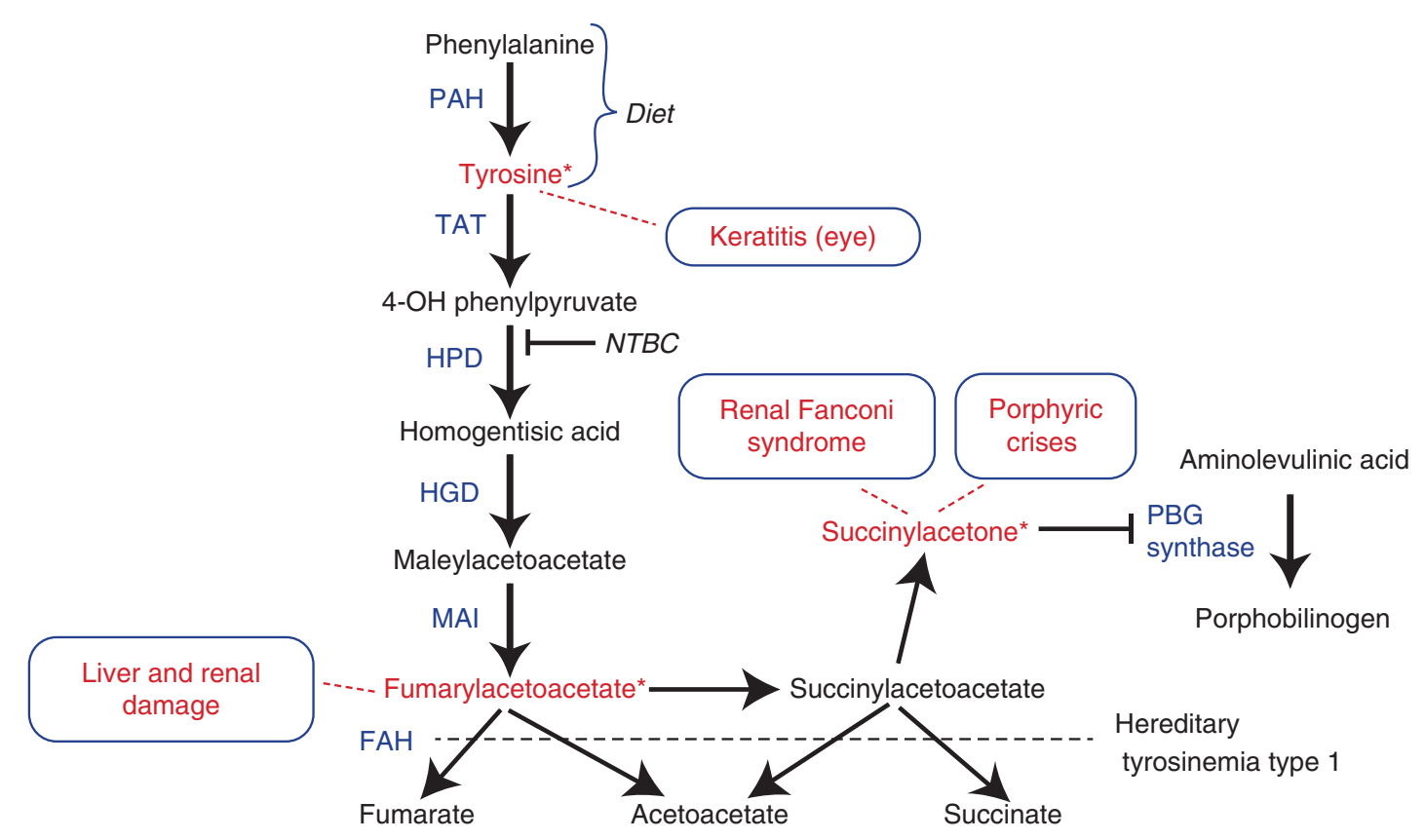

Figure 1 The abnormalities in the pathway of tyrosine metabolism in tyrosinemia type I. Tyrosine is provided both directly from dietary sources and by direct conversion of dietary derived phenylalanine through the activity of phenylalanine hydroxylase (PAH). The catabolic enzymatic activity deficient in tyrosinemia type I (HT-1) is indicated (fumarylacetoacetate hydrolase (FAH)). The abnormally accumulated products due to FAH deficiency are indicated along with their clinical effects. Keratitis is not observed in untreated HT-1 patients but when NTBC therapy is used, it produces elevations of blood tyrosine, which can produce ophthalmologic complications, including keratitis. Succinylacetone is derived from accumulated succinylacetate and is directly associated with renal and neurologic effects (Fanconi renal tubular syndrome, porphyric type crises) and directly inhibits the pathway for heme synthesis at the porphobilinogen synthase activity step. The accumulation of increased levels of $\delta$-aminolevulinic acid is associated with the neurologic (porphyric-like) crises observed in untreated HT-1. Fumarylacetoacetate accumulation is felt to be directly associated with the observed ongoing hepatic and renal damage.

developed hepatic or neurological complications. An alternative option with apparently fewer complications has become available over the last two decades through the introduction of successful pharmacologic therapy with NTBC. 6,22

The mammalian tyrosine catabolic pathway was described in the early 1950s by Edwards and Knox. ${ }^{23}$ Fumarylacetoacetate (FAA) is the natural substrate of FAH, but FAH also uses succinylacetoacetate (SAA) as a substrate (Figure 1). Both FAA and SAA accumulate in FAH deficiency. ${ }^{1}$ The mechanism of the reduction of FAA to SAA has not been established, but it is probably catalyzed by a yet uncharacterized enzyme, FAA-reductase. ${ }^{24}$

Deficiency of FAH would not be expected to result in elevated blood tyrosine, since FAH is five steps removed from the initial catabolic step in tyrosine degradation (Figure 1). Deficiency of a more proximal enzyme in that metabolic pathway, homogentisic acid dioxygenase, the third enzyme, is associated with the medical condition alkaptonuria and the clinical condition is not associated with any hypertyrosinemia. ${ }^{25}$ Therefore, elevated blood tyrosine levels in HT-1 are more likely due to a secondary inhibition of proximal steps in tyrosine degradation and not the deficiency of FAH. ${ }^{26}$ In Fah mutant mice the mRNA for tyrosine amino transferase (Tat), the rate-limiting enzyme in tyrosine degradation, is absent. ${ }^{26}$ The activity of 4-hydroxyphenylpyruvic dioxygenase (HPD), the second step in the tyrosine degradation pathway, is decreased in human HT-1 liver samples. ${ }^{26}$ These observations suggest that the clinical effects associated with HT- 1 are due to other metabolites resulting from FAH deficiency, not the elevation of tyrosine in the blood.

Clinically, elevated plasma levels of tyrosine observed in conditions associated with deficiencies in the tyrosine degradation pathway other than HT-1 are not toxic to the liver or kidney. Elevated blood tyrosine levels cause only dermatological, ophthalmologic, and possibly neurodevelopmental problems in patients with tyrosinemia type II (TAT deficiency, Richner-Hanhardt Syndrome). Patients with tyrosinemia type III (HPD deficiency) also have highly elevated blood tyrosine levels but do not manifest liver disease or renal tubular dysfunction. ${ }^{27-29}$ Tyrosinemia types II and III variably respond to tyrosine-restricted diet therapies, unlike the liver and renal disease of HT-1.

FAA, which accumulates in FAH deficiency, is highly electrophilic and a potent alkylator, causing oxidative damage to the cells in which it is generated by reacting with glutathione and sulfhydryl groups of proteins. ${ }^{30}$ FAA appears to directly damage only the hepatocytes and renal proximal tubules in which it is produced and not adjacent cells. ${ }^{31}$ Because of its rapid reactivity, FAA itself is not found in body 
fluids of patients with HT-1. SAA and SA, derived from reduction of FAA, are the principal diagnostic metabolites of FAA (Figure 1). When effective therapy (i.e., NTBC) to reduce these metabolites is provided to patients with HT-1, the clinical complications associated with FAH deficiency are either prevented (in presymptomatic cases) or ameliorated.

\section{NEWBORN SCREENING FOR HT-1}

Detection of HT-1 through NBS is optimal for diagnosing HT-1 at an asymptomatic stage. Initiation of treatment with NTBC, combined with dietary restriction of phenylalanine and tyrosine in the first months of life, prevents the development of hepatic and renal failure, avoiding the need for liver transplantation. ${ }^{6,32}$ Thus, early diagnosis provided by identification through universal NBS for HT-1 and immediate initiation of therapy should provide the most favorable outcomes for patients.

HT-1 is included in the Secretary of Health and Human Services' Recommended Uniform Screening Panel in the United States. The American College of Medical Genetics and Genomics has also included HT-1 in the core panel of conditions for which every newborn in the United States should be screened. ${ }^{33}$ At the time of the Secretary's considerations, screening of newborn blood tyrosine levels was the method available in all states for identifying newborns for further diagnostic studies. Measurement of tyrosine in blood spots was to be routinely performed by tandem mass spectrometry (MS/MS). However, tyrosine is neither a sensitive nor a specific marker for HT-1. Most commonly, elevated tyrosine levels are due to transient benign hypertyrosinemia in newborns. ${ }^{1}$ Elevated tyrosine with or without elevated methionine could also be seen in premature babies, sick babies on total parenteral nutrition, mitochondrial depletion syndromes, or other metabolic or nonmetabolic liver diseases, including tyrosinemia types II and III. Furthermore, many infants with HT-1 do not have elevated blood tyrosine levels at less than 48 hours of life, the time at which blood is typically collected for NBS. ${ }^{1}$

$\mathrm{SA}$ is a specific and sensitive marker for HT-1. It has been used as a primary marker in blood in the NBS program of Quebec, Canada, where the incidence of HT-1 is 1 in 20,000 live births. ${ }^{34}$ An alternative method of measuring SA in dried blood spots by MS/MS was subsequently developed. ${ }^{35}$ This method used leftover blood spots previously extracted with methanol for acylcarnitine and amino acid analysis. Some NBS programs in the United States have adopted this method as a second-tier test approach using initial tyrosine screening values. SA is measured only when the levels of tyrosine are above a certain cutoff value (for example, tyrosine $>150 \mu \mathrm{mol} / \mathrm{L}) .^{36,37}$ This strategy is not recommended, because some infants with HT-1 may have normal tyrosine levels. It is estimated that $28 \%$ of patients may be missed if this approach is used. ${ }^{37}$ It is crucial to measure SA as the primary marker for HT-1. However, measurements of SA as a first-tier test were initially limited by the need for separate assay protocols and additional MS/MS equipment. Prior to 2008, some state NBS laboratories therefore could not afford to implement this marker as their first-tier assay. In 2008, Turgeon et al. developed an assay for the simultaneous measurement of SA, amino acids and acylcarnitines by flow injection MS/MS. ${ }^{38}$ This method does not require an additional MS/MS, and the same blood spot and the same MS/MS equipment used for other markers can be used for the detection of SA.

The American College of Medical Genetics and Genomics now recommends that SA be measured as the primary marker to screen for HT-1 in all states. ${ }^{33}$ Currently, most states in the United States and provinces in Canada measure blood spot SA with or without tyrosine levels to detect patients with HT-1 through NBS. A few states continue to measure tyrosine as a sole marker and some do not screen for HT-1 at all, but these states are transitioning toward implementing $\mathrm{SA}$ as a primary marker for the NBS of HT-1. There is supportive published discussion that NBS using MS/MS identification of SA in NBS blood spots is the best current approach for early identification of HT-1. ${ }^{8,39}$

\section{Recommendation 1.1}

Blood SA should be used as the primary marker to detect patients with HT-1 through NBS. Nominal: 100\% strongly agree. Evidence quality $\mathrm{B}$.

\section{Recommendation $\mathbf{1 . 2}$}

Tyrosine as a primary marker for NBS of HT- 1 is not recommended. Nominal: $78 \%$ strongly agree; $22 \%$ agree. Evidence quality D.

\section{Newborn screening: confirmatory testing/diagnosis}

Newborns referred to metabolic centers for elevated tyrosine and/or SA for HT-1 should be seen as soon as possible for clinical and laboratory evaluations. The most important initial test is blood or urine SA level. If there is high suspicion for HT-1, plasma amino acids (PAA) and liver function tests including prothrombin time (PT), international normalized ratio (INR), partial thromboplastin time (PTT) and $\alpha$-fetoprotein (AFP) should be evaluated at the first visit. PAA will help to differentiate tyrosinemia types II and III from HT-1 in those cases where the children were detected by an elevated tyrosine level but do not have detectable SA. Additional considerations should include liver disease, prematurity, concurrent use of total parenteral nutrition, or mitochondrial depletion syndrome. ${ }^{40}$ It is advisable to follow the American College of Medical Genetics and Genomics guidelines for NBS of infants with hypertyrosinemia if the subsequent SA determinations are negative. ${ }^{41}$ Importantly, documentation of plasma SA levels in the normal range is mandatory before pronouncing a child negative for HT- $1 .{ }^{33}$ Blood chemistries for future comparisons should be obtained for any patient with an elevated SA, as outlined in Table 1. Except for AFP and plasma tyrosine levels, most of these laboratory values are expected to be normal if obtained within the first few weeks of 
Table 1 Evaluation and follow-up of HT-1 patients identified by newborn screening

\begin{tabular}{|c|c|c|c|c|c|c|c|}
\hline \multirow[t]{2}{*}{ Evaluation } & \multirow{2}{*}{$\begin{array}{l}\text { Initiation of } \\
\text { therapy (baseline) }\end{array}$} & \multicolumn{2}{|c|}{ First year of life } & \multicolumn{3}{|c|}{ From 1 year to 5 years of age } & \multirow{2}{*}{$\begin{array}{l}\text { After } 5 \text { years } \\
\text { of age }\end{array}$} \\
\hline & & Monthly & $\begin{array}{c}\text { Every } \\
3 \text { months }\end{array}$ & $\begin{array}{c}\text { Every } \\
3 \text { months }\end{array}$ & $\begin{array}{c}\text { Every } \\
6 \text { months }\end{array}$ & Yearly & \\
\hline \multicolumn{8}{|l|}{ HT-1 markers } \\
\hline $\begin{array}{l}\text { Blood succinylacetone }{ }^{a} \\
\text { (plasma/ blood on filter paper) }\end{array}$ & $x$ & $x^{b}$ & & $\mathrm{x}$ & & & Every 6 months \\
\hline $\begin{array}{l}\text { Urine succinylacetone (only if } \\
\text { blood is not available) }\end{array}$ & $x$ & $x$ & & $x$ & & & Every 6 months \\
\hline Blood NTBC concentration ${ }^{a}$ & & $x$ & & $x$ & & & Every 6 months \\
\hline $\begin{array}{l}\text { Plasma amino acids (plasma/ } \\
\text { blood on filter paper) }\end{array}$ & $x$ & $x^{b}$ & & $x$ & & & Every 6 months ${ }^{c}$ \\
\hline \multicolumn{8}{|l|}{ Laboratories for HT-1 monitoring } \\
\hline $\begin{array}{l}\text { CBC: hemoglobin, hematocrit, } \\
\text { WBC, platelet count }\end{array}$ & $x$ & & $x$ & & & $x$ & Yearly \\
\hline \multicolumn{8}{|l|}{ Liver evaluation } \\
\hline Serum AFP concentration & $x$ & $x$ & & & $x$ & & Every 6 months $^{d}$ \\
\hline PT & $x$ & $x^{e}$ & & & & $x$ & Yearly \\
\hline PTT & $x$ & $x^{e}$ & & & & $x$ & Yearly \\
\hline ALT/AST & $x$ & & $x^{e}$ & & & $x$ & Yearly \\
\hline $\begin{array}{l}\text { Imaging: CT or MRI (with } \\
\text { contrast) or ultrasound } d^{f, g}\end{array}$ & $x$ & & & & & $x^{c}$ & Yearlyc \\
\hline \multicolumn{8}{|l|}{ Renal studies } \\
\hline Renal imaging (ultrasound) ${ }^{h}$ & $x$ & & & & & & \\
\hline $\begin{array}{l}\text { Blood chemistries: bicarbonate, } \\
\text { BUN, creatinine }\end{array}$ & $x$ & & & & & $x$ & Yearly \\
\hline Blood calcium and phosphate & $x$ & & & & & $x$ & Yearly \\
\hline Urine analysis & $x$ & & & & & & \\
\hline \multicolumn{8}{|c|}{ Standard dietary management laboratories: if not included above, see text for more information } \\
\hline $\begin{array}{l}\text { Developmental evaluation/ } \\
\text { neuropsychology assessment }\end{array}$ & & & & & & & $\begin{array}{l}\text { Before school } \\
\text { age }\end{array}$ \\
\hline $\begin{array}{l}\text { Ophthalmology: slit-lamp } \\
\text { examination }\end{array}$ & When symptomatic o & at increased & k (see text fo & hore informa & & & \\
\hline
\end{tabular}

AFP, $\alpha$-fetoprotein; ALT, alanine transaminase; AST, aspartate transaminase; BUN, blood urea nitrogen; CBC, complete blood count; CT, computed tomography; MRI, magnetic resonance imaging; NTBC,2-[2-nitro-4-trifluoromethylbenzoyl]-1,3-cyclohexanedione; PT, prothrombin time; PTT, partial thromboplastin time; WBC, white blood count.

Nominal group recommendation: $56 \%$ strongly agree and $44 \%$ agree

aphysician has choice of blood NTBC or SA. ${ }^{b}$ Can switch to filter paper monitoring if the same is used over time for the baseline. ${ }^{C}$ As needed based on compliance. ${ }^{\mathrm{d}}$ Any increase, immediate imaging. ${ }^{~}$ Until normal. ${ }^{\mathrm{f}} \mathrm{Need}$ to wait 1 week post initiation of NTBC treatment to avoid anesthetic-induced porphyric crisis. ${ }^{9}$ Ultrasound: validity is operator-dependent. "While doing liver imaging, and then only as clinically indicated after this.

life. Once diagnosis is confirmed, NTBC and dietary therapies should be initiated immediately (see "Management: NTBC Drug Therapy for HT-1" and "Nutritional management of HT-1" below). Similarly, if a patient is identified through NBS or clinically with HT-1, it is imperative that siblings are tested immediately for the presence of SA so that effective treatment also can be initiated. ${ }^{1}$

Based on the literature, practitioner survey, and clinical experience, all the nominal group members strongly agreed that an HT-1 diagnosis should be confirmed by measuring blood or urine SA as soon as possible following a positive NBS result. The increasing clinical availability of testing for blood SA should soon make this marker the preferred clinical standard of care. ${ }^{8,42}$

\section{Recommendation 1.3}

Following a positive NBS result, as soon as possible:

(a) Confirm HT-1 with diagnostic blood or urine SA (using a new sample), and

(b) Obtain additional recommended tests (Table 1): liver function tests (PT, aPTT, international normalized ratio, levels of aspartate transaminase and/or alanine transaminase), AFP, PAA, electrolytes and glucose. Nominal: $100 \%$ strongly agree. Evidence quality D.

\section{Recommendation 1.4}

If a child is diagnosed with HT-1, HT-1 should be ruled out in siblings. Nominal: $100 \%$ strongly agree. Evidence quality D. 


\section{GENOTYPE/PHENOTYPE}

$F A H$, the gene encoding $\mathrm{FAH}$, is located at chromosome $15 \mathrm{q} 23$ and is composed of 14 exons. Approximately 100 different mutations responsible for HT-1 have been identified in $F A H^{43}$ A small number of mutations account for the majority of clinically identified cases (Table 2). These common mutations exist because of founder effects in geographic locations. For instance, the highest concentration of the IVS12+5G > A mutation was reported in the FrenchCanadian population. ${ }^{44,45}$ This mutation, now designated c. $1062+5 \mathrm{G}>\mathrm{A}$, is prevalent in Quebec owing to a historical founder effect in the French-Canadian population of that province. ${ }^{46}$ The same mutation is common in northern Europe and contributes $45 \%$ of the alleles responsible for HT-1 in this geographic region. The p.W262X mutation is found in $80 \%$ of the cases from Finland and the IVS6-1G $>$ T (c.554-1G > T) mutation is responsible for $64 \%$ of the pathogenic alleles in Southern Europe (Table 2) ${ }^{43}$

Because of the ethnic diversity in the US population, there is a greater dispersion of pathogenic variants. The two most common are the c. $1062+5 \mathrm{G}>\mathrm{A}$ (IVS12+5G $>$ A) from northern Europe and c.554-1G $>\mathrm{T}$ (IVS6-1G $>\mathrm{T}$ ) from southern Europe. The frequency of other pathogenic variants vary from a high of $20 \%$ (p.P261L) to single pathogenic nucleotide changes. ${ }^{47}$ Targeted molecular analysis of FAH should be performed, if possible, for all cases of confirmed NBS positive SA findings as well as in patients suspected to have HT-1 clinically but without clear positive SA results. Both types of cases, clinical HT-1 (FAH mutation) without circulating SA, and persistent SA due to maleylacetoacetic isomerase deficiency (mutation in GSTZ1, not FAH) without HT-1-like clinical symptoms, have recently been described. ${ }^{48,49}$

\section{Recommendation 2.1}

Molecular testing of $F A H$, encoding FAH, should be done for confirmation of HT-1, but treatment should not be delayed while awaiting the results. Nominal: 100\% strongly agree. Evidence quality D.

\section{Genetic counseling}

Genetic counseling should be provided to parents with affected children and the $25 \%$ recurrence risk emphasized

\begin{tabular}{lll}
$\begin{array}{l}\text { Table } 2 \text { FAH gene mutations in geographic regions } \\
\text { Mutations }\end{array}$ & $\begin{array}{l}\text { Geographic } \\
\text { location }\end{array}$ & $\begin{array}{l}\text { Frequency in } \\
\text { population }\end{array}$ \\
\hline c.1062+5G $>$ A $($ IVS12+5G $>$ A) & French Canada & $86 \%$ \\
& Northern Europe & $46 \%$ \\
\hline p.W262X & Finland & $80 \%$ \\
\hline c.554-1G $>$ T (IVS6-1G > T) & Southern Europe & $64 \%$ \\
\hline p.G337S & Norway & $58 \%$ \\
\hline p.Q64H & Pakistan & $92 \%$ \\
p.D233V & Turkey & $94 \%$ \\
\hline
\end{tabular}

${ }^{\text {aT }}$ The two most common mutations in the United States. with regard to future pregnancies. Counseling should include the availability of targeted molecular analysis for confirmation of diagnosis, detection of at-risk parents, prenatal diagnostics, and the natural history of HT-1-affected children prior to and following the availability of NTBC. ${ }^{47}$

\section{Recommendation 3.1}

Genetic counseling should be provided to parents with affected children and the $25 \%$ recurrence risk with regard to future pregnancies should be discussed in detail. Nominal: $78 \%$ strongly agree; $11 \%$ agree; $11 \%$ disagree. Evidence quality D.

\section{CLINICAL INFORMATION: GENERAL CONSIDERATIONS}

The accumulation of toxic metabolites in HT-1 produces a number of severe clinical complications owing to their effects on multiple organs (Figure 1). Before the introduction of NTBC therapy, hepatic failure was followed by hepatic transplantation as the only option for survival. Development of HCC was observed in $17-37 \%$ of affected children. ${ }^{4,5}$ Similarly, proximal tubular dysfunction, eventually leading to chronic renal disease, produced failure to thrive with hypophosphatemic rickets and renal tubular acidosis (RTA). Neurological effects included hypertonic posturing resembling opisthotonus, neuropathic pain, hypertension, and muscular weakness. Some crises lead to paralysis, with respiratory failure. ${ }^{2}$ All of these complications have been shown to be preventable with NTBC therapy. ${ }^{11,32,50,51}$ Because HT-1 survival rates have improved as a consequence of NTBC therapy, other complications, including neurodevelopmental impairments and ophthalmologic involvement, are being noted. Despite NBS, there still will be patients identified by clinical symptoms and these patients will need to be followed in a slightly different manner, sometimes with more focused organ system evaluation (Table 3). However, both groups of patients at diagnosis require immediate initiation of NTBC and diet therapy for optimal results. Per the US Food and Drug Administration (FDA) drug label, initial dosing of NTBC should be $1.0 \mathrm{mg} / \mathrm{kg} / \mathrm{day}$, given in two divided doses. Blood levels of NTBC can be determined and dosing adjusted to maintain plasma levels at $40-60 \mu \mathrm{mol} / \mathrm{L}$. In older children, once-a-day dosing with monitoring of plasma NTBC may be considered for the sake of convenience. ${ }^{52}$ In all cases, the lowest dose of NTBC that completely suppresses urine and/or plasma SA (use the normal value determined by the reference laboratory utilized) should be prescribed.

\section{Management: NTBC drug therapy for HT-1}

NTBC is a triketone that was evaluated by the chemical industry as an herbicide (Figure 2). ${ }^{1}$ It was successful as an herbicide; however, in the evaluation of its safety profile, rats exposed to NTBC developed elevated plasma tyrosine levels and ocular lesions. The ocular lesions were caused by tyrosine crystals within the cornea. Further studies documented that NTBC was a potent inhibitor of 4-hydroxyphenylpyruvate 
Table 3 Clinical monitoring

\begin{tabular}{|c|c|}
\hline Evaluation & Notes \\
\hline \multicolumn{2}{|l|}{ Summary of routine evaluations } \\
\hline \multicolumn{2}{|l|}{ Blood (or urine) succinylacetone } \\
\hline Blood NTBC concentration & After initiation of treatment \\
\hline \multicolumn{2}{|l|}{$\begin{array}{l}\text { Plasma amino acids } \\
\text { (phenylalanine, tyrosine) }\end{array}$} \\
\hline \multicolumn{2}{|l|}{$\begin{array}{l}\text { CBC: hemoglobin, hematocrit, } \\
\text { WBC, platelet count }\end{array}$} \\
\hline \multicolumn{2}{|l|}{ PT/PTT } \\
\hline \multicolumn{2}{|l|}{ CMP } \\
\hline \multicolumn{2}{|l|}{ AFP } \\
\hline \multicolumn{2}{|l|}{ Urine: see renal evaluation below } \\
\hline \multicolumn{2}{|l|}{ Liver evaluation } \\
\hline \multicolumn{2}{|l|}{ Serum AFP concentration } \\
\hline \multicolumn{2}{|l|}{ PT } \\
\hline \multicolumn{2}{|l|}{ PTT } \\
\hline ALT/AST/GGT & $\begin{array}{l}\text { One of either ALT or AST is good; } \\
\text { GGT if patient is symptomatic }\end{array}$ \\
\hline \multicolumn{2}{|l|}{ Bilirubin including direct } \\
\hline \multicolumn{2}{|l|}{ Albumin } \\
\hline Alkaline phosphatase & $\begin{array}{l}\text { For rickets; if elevated, consider } \\
\text { wrist radiography, consider } \\
\text { vitamin D level }\end{array}$ \\
\hline $\begin{array}{l}\text { Imaging: ultrasound with } \\
\text { periodic MRI or CT(with contrast) }\end{array}$ & $\begin{array}{l}\text { Modality dependent on indivi- } \\
\text { dual clinical circumstances (see } \\
\text { text) }\end{array}$ \\
\hline \multicolumn{2}{|l|}{ Renal evaluation } \\
\hline \multicolumn{2}{|l|}{ Ultrasound } \\
\hline \multicolumn{2}{|l|}{$\begin{array}{l}\text { Blood chemistries: bicarbonate, } \\
\text { BUN, creatinine }\end{array}$} \\
\hline \multicolumn{2}{|l|}{ Blood calcium and phosphate } \\
\hline \multicolumn{2}{|l|}{ Urine analysis } \\
\hline \multicolumn{2}{|l|}{ Urine amino acids } \\
\hline \multicolumn{2}{|l|}{$\begin{array}{l}\text { Urine calcium, phosphate, } \\
\text { creatinine (TRP) }\end{array}$} \\
\hline \multicolumn{2}{|l|}{ Urine $B 2$-microglobulin } \\
\hline \multicolumn{2}{|l|}{ Other evaluation } \\
\hline Nutrition assessment & See text for nutrition \\
\hline $\begin{array}{l}\text { Developmental evaluation/ } \\
\text { neuropsychology assessment }\end{array}$ & By school age or as needed \\
\hline $\begin{array}{l}\text { Ophthalmology: Slit lamp } \\
\text { examination }\end{array}$ & $\begin{array}{l}\text { When symptomatic or at } \\
\text { increased risk }\end{array}$ \\
\hline
\end{tabular}

AFP, blood alphafetoprotein; ALT, alanine transaminase; AST, aspartate transaminase; BUN, blood urea nitrogen; CBC, complete blood count; CMP, complete metabolic panel plus phosphate; GGT, gamma glutamyl transpeptidase; NTBC, 2 [2-nitro-4-trifluoromethylbenzoyl]-1,3-cyclohexanedione; PT, prothrombin time; PTT, partial thromboplastin time; TRP, tubular reabsorption of phosphate; WBC, white blood count

Nominal group recommendation: 33\% strongly agree, 56\% agree and 11\% neutral.

dioxygenase (HPD), which catalyzes conversion of 4hydroxyphenylpyruvate to homogentisic acid ${ }^{53}$ (Figure 1). Sven Lindstedt recognized the potential value of NTBC for the treatment of HT-1. By blocking the proximal tyrosinemia pathway, NTBC minimizes the formation of FAA and maleylacetoacetic. It was this keen insight that led to the original clinical trial with five patients, which documented the rapid reversal of clinical symptoms. ${ }^{22}$

NTBC was evaluated by the FDA in an open-label study involving over 180 pediatric subjects from 25 countries at 87 sites. Treatment was associated with a 4-year survival probability of $88 \%$ for children under 2 years of age versus historical controls showing a survival rate of $29 \%$. Both groups received dietary restriction therapy. In May 1995, NTBC was designated an Orphan Drug by the Office for Orphan Product Development. At that time, there were fewer than 100 children in the United States with HT-1. This enabled expedited review by the FDA. The FDA approved NTBC in January 2002. ${ }^{54}$

NTBC has been tested with purified human HPD and has been shown to have an inhibitory constant of $5 \mathrm{nM} .{ }^{55}$ Thus, a concentration of $35 \mu \mathrm{M}$ will inhibit $99.9 \%$ of the activity of HPD. From a clinical perspective one can monitor the plasma concentration of NTBC and adjust the daily dosage to maintain a plasma level of between 40 to $60 \mu \mathrm{M}$ and be confident of satisfactory inhibition of the proximal tyrosine catabolic pathway. The half-life of NTBC has been measured in healthy human subjects and found to be approximately 54 hours. ${ }^{53}$ Because of this long half-life, a single daily dose of NTBC is satisfactory for maintaining inhibition of HPD. ${ }^{52}$ Basing the dose on measured plasma NTBC concentration is more reliable than basing it on body weight. For older children or young adults, this may result in a lower daily dose of NTBC than using the standard dosage of $1 \mathrm{mg} / \mathrm{kg}$ body weight that is recommended for infants.

NTBC should be started as soon as the diagnosis of HT-1 is suspected either from NBS results or clinical presentation. The recommended starting dose is $1 \mathrm{mg} / \mathrm{kg} /$ day (package insert). However, there are differing opinions and practices regarding the appropriate dose of NTBC. Doses as low as $0.55 \mathrm{mg} / \mathrm{kg}$ per day have been used with success. ${ }^{56}$

While some practitioners routinely monitor plasma NTBC concentrations and adjust the dose accordingly, there are no evidence-based guidelines about the target therapeutic goal, and "recommended" plasma concentrations range from 30 to $70 \mu \mathrm{mol} / \mathrm{L}$. Some suggest that the dose should be reduced to the minimum required to maintain biochemical control; some practitioners recommend once-daily dosing in older patients. ${ }^{9}$ NTBC dosing should be sufficient to completely suppress plasma and urine SA detection, and normalize liver and renal function. Tests of liver function including coagulation (PT, aPTT) should be routinely undertaken as an indication of early HT-1-associated hepatic disease. In addition, periodic complete blood counts should be obtained, since transient thrombocytopenia and leukopenia were reported in the FDA trials (Table 3). SA, in either plasma or urine, should be below detectable limits (or within the limits of normal established by the reference laboratory). The dose of NTBC should be increased if the SA level increases once patient adherence has been confirmed. 


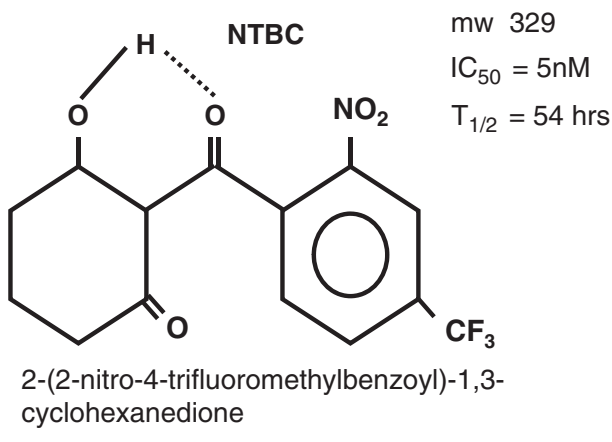

Figure 2 Structure of 2-[2-nitro-4-trifluoromethylbenzoyl]-1,3-cyclohexanedione (NTBC, nitisinone). mw: molecular weight. $I C_{50}$ : The molar concentration of NTBC that will inhibit $50 \%$ of the enzymatic activity of $\mathrm{p}-\mathrm{OH}$-phenylpyruvic acid oxidase. $\mathrm{T}_{1 / 2}$ : The half-life of NTBC concentration in the plasma of healthy young adults.

\section{Recommendation 4.1}

NTBC and dietary therapy should be initiated as soon as possible following diagnosis of HT-1. Nominal: $89 \%$ strongly agree; $11 \%$ agree. Evidence quality B.

\section{Recommendation 4.2}

In general, NTBC treatment should be initiated at $1.0 \mathrm{mg} / \mathrm{kg} /$ day. Nominal: $78 \%$ strongly agree; $22 \%$ agree. Evidence quality D.

\section{Recommendation 4.3}

The total calculated amount of NTBC should be divided into two doses daily in the first year of life. Thereafter, single daily dosing can be considered. Nominal: $67 \%$ strongly agree; $33 \%$ agree. Evidence quality D.

\section{Recommendation 4.4}

The minimum dose of NTBC should be used to achieve a blood concentration of $40-60 \mu \mathrm{mol} / \mathrm{L}$ and/or blood SA level within the normal range of the reference laboratory. Nominal: $56 \%$ strongly agree; $33 \%$ agree; $11 \%$ neutral. Evidence quality $\mathrm{D}$.

NTBC is only minimally metabolized and it is unable to inhibit or induce human cytochrome P450 enzymes. It has no known interactions with other drugs and should therefore be safe in combination with other medications. ${ }^{57}$

\section{Recommendation $\mathbf{5 . 1}$}

Standard medication dosing and preventive care, including routine immunizations, can be used with patients treated with NTBC. Nominal: $62 \%$ strongly agree; $25 \%$ agree; $12 \%$ neutral. Evidence quality D.

\section{Management of acute clinical presentations of HT-1}

Many patients will be diagnosed through NBS, and the majority of these will be asymptomatic at presentation. In these patients, NTBC and a low phenylalanine/tyrosine restricted diet should be started without delay. Suggested initial laboratory and imaging studies are shown in Table 1 for patients diagnosed by NBS and in Table 3 for others, including those diagnosed via clinical presentations.

Some patients not identified through NBS may be acutely ill and require emergency management. Manifestations of acute liver disease include abnormal synthetic function with coagulopathy, hypoglycemia, and/or elevated transaminases, ${ }^{9}$ and may progress to multiorgan failure. It is important that supportive consultation with pediatric hepatologists and/or critical care be sought during this period of acute deterioration. Initial efforts should be directed at managing these lifethreatening symptoms, and may involve ventilatory and pressor support as well as treatment of underlying infections. Intravenous $10 \%$ dextrose/normal saline solutions-initially infused at 1.5-2.0 times the normal IV fluid maintenance rate for age, a rate that inhibits production of $\delta$-ALA, which is associated with the neurologic crises and stimulates limitation of tyrosine catabolism - should be used to maintain normoglycemia. Administration of fresh frozen plasma and vitamin $\mathrm{K}$ (to correct coagulopathy) should be similarly considered. Treatment of metabolic acidosis caused by RTA may be required. NTBC should be initiated immediately at $1 \mathrm{mg} /$ $\mathrm{kg} /$ day. The response to NTBC is usually rapid, and urinary SA should normalize after 24 hours, with clinical response occurring within 1 week. If there is no improvement or if the patient is in acute severe liver failure, the dose should be increased to $2 \mathrm{mg} / \mathrm{kg} .{ }^{11}$ If there is no response after about 1 week following NTBC therapy, consideration for hepatic transplantation should be initiated. In cases of persistent severe coagulopathy and/or encephalopathy, these considerations may need to begin after only 2-3 days. When the patient is clinically stable, a low phenylalanine/tyrosine diet should be initiated under the care of a metabolic dietitian. It is important to introduce a small amount of complete protein $(0.25-0.5 \mathrm{mg} / \mathrm{kg} /$ day $)$ by $36-48$ hours, even if introduction is by total parenteral nutrition, to avoid the continuing problems of ongoing catabolism and stimulation of the tyrosine catabolic pathway.

In some laboratories, SA is reported as "undetectable" in non-HT-1 individuals but this may reflect the low sensitivity of their technique of detection. Clinicians should be made aware of how the reported "normal" control range of SA is reported (e.g., undetectable vs. $<1 \mu \mathrm{M}$ ). Following this normalization, some clinical laboratory results could take weeks (signs of Fanconi syndrome including hypophosphatemia, aminoaciduria and/or metabolic acidosis) or months (AFP) to actually reach normal values. ${ }^{58}$ Repeat examination of the laboratory indicators cited in Table 3 will therefore have to be individualized for each patient, choosing from some of the surveillance patterns indicated in Table 1 . Because the complication rates in patients presenting and being treated after 1 month of age are higher than in those immediately treated following positive NBS, surveillance for hepatocellular carcinoma has to be more frequent than indicated in Table 1 (details in "Hepatic disease" section below). 


\section{Nutritional management of HT-1}

The goal of nutrition management in NTBC-treated patients is twofold: (i) restrict the amino acids phenylalanine and tyrosine to maintain PAA concentrations within treatment range; and (ii) support normal growth and development. ${ }^{59}$ Since approximately $75 \%$ of dietary phenylalanine is hydroxylated to form tyrosine, phenylalanine must be restricted in the diets of affected patients. ${ }^{60}$ To accomplish the dual restriction of phenylalanine and tyrosine, a decreased amount of intact dietary protein as recommended for age must be prescribed. In order to meet protein, energy, and nutrient requirements, it is necessary to use medical foods, which are amino acid mixtures devoid of phenylalanine and tyrosine. Many such medical foods are available (e.g., Tyrex 1, Tyros 1, Tyr coolers). In addition, modified low-protein foods are another manufactured source of low-phenylalanine and lowtyrosine nutrition. The intake of these two types of modified/ medical foods provides energy, variety, and satiety to patients on restricted low-phenylalanine and tyrosine (low-naturalprotein) diets. The recommended daily protein intakes are higher than those for normal diets because the proteins from medical foods have lower absorptive efficiency. ${ }^{61}$ To achieve the fastest rate of declination in tyrosine on diagnosis in infants, $20-30 \mathrm{kcal} / \mathrm{oz}$ phenylalanine- and tyrosine-free formulas with no intact protein may be given for up to 48 hours. For young infants, one should provide for total energy intakes of above $120 \mathrm{kcals} / \mathrm{kg} /$ day and protein intakes from medical foods of $3.5 \mathrm{~g} / \mathrm{kg}$ to prevent catabolism. ${ }^{62}$

Introduction of regular infant formula or breast milk should be adjusted to achieve $185-550 \mathrm{mg}$ /day of phenylalanine and 95-275 mg/day of tyrosine. ${ }^{62}$ Advances in diet are achieved by adjusting the intact protein and utilizing medical foods and a vegetarian diet, along with modified low-protein foods. Nutritional intake should meet the age-appropriate energy and nutrient needs of individuals based on the Recommended Dietary Allowances. ${ }^{63}$ This plan should be developed simultaneously with monitoring the diet through food records and analysis software to assure nutrient adequacy for age.

It is important to obtain periodic ongoing PAAs with special focus on phenylalanine and tyrosine concentrations to prevent deficiencies. PAAs should be maintained within normal ranges and with the goal of plasma tyrosine concentration of $200-600 \mu \mathrm{mol} / \mathrm{L}$ (normal: $35-90 \mu \mathrm{mol} / \mathrm{L}$ ) and plasma phenylalanine concentration of $20-80 \mu \mathrm{mol} /$ L. ${ }^{47,64,65}$ If blood phenylalanine levels fall below $20 \mu \mathrm{mol} / \mathrm{L}$, additional protein should be added to the diet from milk or foods. ${ }^{64}$ If plasma phenylalanine concentrations continue to be low in the face of increased intact protein, some clinicians prescribe phenylalanine supplements. ${ }^{66}$ It is equally important to monitor comprehensive nutrient intake frequently to prevent the deficiencies in vitamins and minerals that may accompany a low-protein diet. ${ }^{67}$

Management of this complex diet therapy requires a team that includes individuals with biochemical genetics training and certified registered dietitians.

\section{Recommendation $\mathbf{6 . 1}$}

Restrict dietary tyrosine to maintain plasma tyrosine concentrations of $200-600 \mu \mathrm{mol} / \mathrm{L}$. Nominal: $62 \%$ strongly agree; 25\% agree; $12 \%$ neutral. Evidence quality C.

\section{Recommendation $\mathbf{6 . 2}$}

Adjust phenylalanine intake to maintain plasma phenylalanine concentrations within the normal range of the reference laboratory. Use intact protein or phenylalanine supplementation, if necessary. Nominal: 38\% strongly agree; $62 \%$ agree. Evidence quality D.

\section{Recommendation $\mathbf{6 . 3}$}

Recommend age-appropriate daily requirements of vitamins and minerals to support growth in children and health maintenance in adults. Nominal: $88 \%$ strongly agree; $12 \%$ agree. Evidence quality $\mathrm{C}$.

It is unclear whether there is a correlation between lower tyrosine levels and absence of clinical complications from HT- $1 .{ }^{11}$ However, dietary restriction is necessary to avoid the complications that are both known and beginning to be recognized as associated with elevated plasma tyrosine levels (described in "Clinical Findings in HT-1" below).

\section{Bone mineral density}

The risk of osteopenia is similar to that of other individuals on a restricted diet. If RTA is present, however, the risk is increased and monitoring should occur more frequently.

\section{Hepatic disease}

\section{CLINICAL FINDINGS IN HT-1}

Infants with HT-1 demonstrate acute liver failure as early as a few weeks of age. Historically, a continuum of disease severity was observed, ranging from hepatic dysfunction and failure within the first months of life to a chronic illness with hepatic cirrhosis. Coagulopathy is an early sign, manifesting even without other clinical signs of hepatic dysfunction. ${ }^{68}$ Hepatomegaly, hypoglycemia, direct hyperbilirubinemia, elevated transaminases, and hypoalbuminemia may not be present during initial follow-up of positive NBS. Neonatal hypoglycemia without other signs of hepatic dysfunction may be observed, but may resolve quickly. As presymptomatic infants with HT-1 are identified by NBS, physicians should obtain baseline hepatic studies for ongoing comparisons with increasing age (Tables $\mathbf{1}$ and 3). Hyperbilirubinemia, in the absence of other abnormal hepatic studies, is NOT helpful in the initial diagnosis of HT-1. Its presence may imply another type of liver problem. Blood AFP is an important marker, which is almost always elevated in early infancy. However, physicians should be careful in the interpretation of elevated AFP levels in young infants since this is commonly a normal finding in healthy neonates, as a remnant of the AFP which constitutes the major circulating protein in fetal blood. ${ }^{69,70}$ AFP rapidly declines after birth and the values observed in HT-1 are often 10 -fold those observed in normal neonates ( $<1$ month old). Ongoing AFP measurements are mandatory 
for following HT-1 patients, as they are a useful indicator of developing HCC. However, elevated AFP levels are not diagnostic for HT-1. ${ }^{71}$ In contrast, elevated blood or urine SA levels are diagnostic for HT-1. SA should return to undetectable (or normal per reference laboratory) levels with NTBC therapy and throughout life as evidence of compliance with drug therapy. There is one report of a child with "silent" HT-1, without elevated tyrosine or SA, that was identified by liver cirrhosis and hepatocellular carcinoma, requiring $F A H$ gene sequence for diagnosis. ${ }^{48}$

A sudden appearance of SA, in contrast to rising AFP levels, is not a marker for the emergence of HCC. It is a sign of noncompliance with NTBC therapy. Ongoing surveillance of hepatic synthetic function (PT, PTT, albumin) and signs of inflammation and disruption of normal hepatic functions (bilirubin, aspartate and alanine aminotransferases, alkaline phosphatase, gamma glutamyl transpeptidase GGT) are recommended. It is expected that these values will remain normal in individuals identified early in infancy by NBS and compliant with NTBC and dietary therapy. Elevated AFP levels should decrease continuously throughout the first year of treatment. If AFP does not decrease consistently or if it increases, imaging should be performed immediately. However, ongoing normal AFP values do not guarantee the absence of HCC. The largest published longitudinal data on HT-1 patients detected by $\mathrm{NBS}^{32}$ noted that if a patient was treated before 1 month of age, no HCC occurred over 20 years of follow-up. Longer-term outcomes, especially the development of HCC, renal disease, ophthalmologic complications, and intellectual delays, are unknown and continued surveillance is warranted.

The emergence of HCC is a particularly complicated issue, with respect to both screening and predictions for its prevention while NTBC therapy is continued. There is robust evidence supporting the association of NTBC and dietary therapy with marked declines in the frequency of HCC $(<1 \%$ if started prior to 1 year of age, $7 \%$ if started between 1 and 2 years of age, $21 \%$ if started between 2 and 7 years of age, $35 \%$ if started after 7 years of age). ${ }^{6}$ This contrasts favorably with historical observations of patients in the pre-NTBC era that reported HCC frequencies of $18 \%$ and $37 \%$ before 10 years of age. ${ }^{4,5}$ Recent studies of HT-1 patients diagnosed during the NTBC treatment era have demonstrated marked reductions in the incidence of HCC, perhaps as low as $<1 \%$ if treated early in infancy. ${ }^{6,32,50}$ Nonetheless, ongoing surveillance is crucial, using periodic blood AFP levels and imaging modalities (ultrasound, computed tomography, magnetic resonance imaging). The optimal periodicity for testing is unclear, with many groups suggesting vigilant screening with both measurement of AFP values and periodic imaging being performed every 3-6 months ${ }^{9-11}$ and immediately if AFP increases. Cases of hepatocellular carcinoma have been reported several years after the initiation of NTBC, even after dramatic declines in the initial elevated AFP levels. ${ }^{71,72}$ It is of note that neither ultrasound, nor computed tomography, nor magnetic resonance imaging can discriminate between all benign and malignant hepatic nodules that appear in up to $75 \%$ of non-NTBC-treated patients. ${ }^{9,32,73-75}$ Prior to the NTBC therapy era, the presence of HCC was an indication for hepatic transplantation in HT-1 patients. ${ }^{76,77}$ Successful hepatic transplantation is expected to both restore liver function and reduce the inherent lifelong high risk of hepatocellular carcinoma in HT-1 patients. ${ }^{78}$

In the current period of NTBC availability, it is unclear if focal resection of primary HCC and ongoing NTBC therapy will have as promising an outcome as hepatic transplantation. Because of the risks associated with either hepatic transplantation and immune suppressive drug therapy, or hepatic resection in the presence of cirrhosis, it is currently unclear which of these two options should be advocated. If transplantation is performed, there are a few practitioners who suggest continuation of the NTBC, since nonhepatic tissues will continue to produce SAA and theoretically produce damaging effects, especially to renal tissue (see "Renal Disease in HT-1" below). Our practitioner management survey suggested that $16 \%(n=3)$ agreed, $58 \%(n=11)$ were neutral, 21\% $(n=4)$ disagreed, and 5\% $(n=1)$ strongly disagreed with the statement "In HT-1 patients who have received a liver transplant, NTBC should continue to be given" (see Supplementary Appendix 1). Our nominal group could not reach a consensus recommendation about this point because there was insufficient available data.

In conclusion, in patients with HT-1, there are very high risks for ongoing severe hepatic disease and malignancy. These risks can be substantially reduced to below $1 \%$ if NTBC treatment is started early in infancy and continued without interruption. Lifelong surveillance for these hepatic complications in HT-1 is mandatory.

\section{Liver transplantation}

Since the availability of NTBC, liver transplantation as a treatment for HT-1 is limited to cases where the individual has a malignancy, has decompensated liver disease refractory to NTBC, or in cases where NTBC is not available. ${ }^{7,77}$ Successful transplantation is expected to both restore liver function and reduce the risk of hepatocellular carcinoma. ${ }^{78}$ A review of 125 HT-1 patients in the UNOS database who were transplanted before 2008 showed 1- and 5-year survivals of 90.4\%. ${ }^{78}$

After transplantation, urine and plasma SA decreases but is not completely suppressed, presumably because of continued production in the kidneys. ${ }^{58}$ Low-normal porphobilinogen synthase activity suggests that the SA may be active. ${ }^{79}$ Although the long-term consequences of this continuous excretion of SA are not well documented, there are theoretical concerns that individuals may develop tubulopathy, RTA, or other renal manifestations after successful liver transplantation. To date, there is no evidence that this occurs.

\section{Recommendation 7.1}

Alpha-fetoprotein and liver imaging should be carried out periodically for early detection of hepatocellular carcinoma. Nominal: $78 \%$ strongly agree; $22 \%$ agree. Evidence quality C. 


\section{Recommendation $\mathbf{7 . 2}$}

Appropriate referrals to other specialists (oncologist/hepatologist/transplant center) should be made in case of progressive liver disease, persistent/progressive elevation of alphafetoprotein, and/or imaging suggesting localized lesion(s). Nominal: $67 \%$ strongly agree; 33\% agree. Evidence quality D.

\section{Recommendation 7.3}

Based on disease pathophysiology, post-transplant patients should have periodic screening for renal disease. Nominal: $67 \%$ strongly agree; $33 \%$ agree. Evidence quality D.

\section{Renal disease in HT-1}

A Fanconi-syndrome-type tubular disorder, characterized by aminoaciduria, glucosuria, phosphaturia, and/or RTA, is typical in untreated HT-1. Onset and severity, however, are variable, with the majority of patients being symptomatic by 6 months of age. Patients in whom renal disease is the predominant presenting feature have been reported. These patients typically demonstrate co-morbid liver involvement of varying severity. Progressive renal disease, not just Fanconi renal syndrome, is a near constant in untreated HT-1.,32 Aside from hypophosphatemic rickets and hypertension, which can occur early in the disease process, longer-term complications include glomerulosclerosis, nephrocalcinosis, and chronic renal failure. Imaging may show abnormal renal architecture with dilated tubules, echogenicity, enlarged kidneys, cysts, and nephrocalcinosis. ${ }^{80}$ The signal for the characteristic apoptosis of renal epithelial cells appears to be FAA, whereas SA appears responsible for the renal tubular damage. ${ }^{81}$

At the time of diagnosis of HT-1, particularly if not in the first few weeks following positive NBS, full investigation of renal involvement should be initiated (Table 3 ). This should include the following:

- Blood: blood urea nitrogen and creatinine, electrolytes including bicarbonate for assessment of RTA, calcium, and phosphate

- Urine: glucose, amino acids, calcium, phosphate, Ca: creatinine ratio, tubular reabsorption of phosphate, total protein and albumin

- Ultrasound of kidneys

- Bone X-ray (wrist, chest, other) and densitometry for evidence of rachitic changes from hypophosphatemia

Standard therapeutic approaches to HT-1 with NTBC and dietary restriction of phenylalanine/tyrosine are associated with reversal (or prevention) of the tubulopathy in nearly all cases within weeks. ${ }^{9,58}$ To assess the ongoing presence of or recovery from RTA and tubulopathy, urine can be periodically analyzed for amino acids, glucose, phosphate (for tubular reabsorption of phosphate), excretion of protein and albumin or $\beta 2$-microglobulin, and $\mathrm{Ca} / \mathrm{Cr}$ ratios compared to plasma. The occurrence of longer-term renal complications, evidenced by elevation of creatinine, the presence of hypertension, and a requirement for increased daily water intake for maintenance of hydration status, is due to irreversible organ damage, which correlates with the length of time of the ongoing presence of SA in blood/urine. Therefore, continuation of NTBC treatment is crucial. ${ }^{9}$

\section{Neurologic crises in HT-1}

Acute peripheral neuropathy presenting with episodes of painful dysesthesias or paralysis, with or without hypertonic posturing, is a well-known condition in untreated patients with HT-1. ${ }^{2}$ This is caused by axonal degeneration, secondary demyelination, and perhaps direct central nervous system neuronal/synaptic dysfunction. Many episodes are preceded or concurrent with vomiting or an ileus-like picture, and may be precipitated by mild illness. Major findings of the neurologic crisis include pain poorly localized in the legs and occasionally abdomen, axial and extensor hypertonia, weakness (sometimes leading to a requirement for mechanical ventilation), hyponatremia (which at times is associated with seizures), and hypertension. Considerable evidence supports the association of abnormal metabolism of $\delta$-aminolevulinic acid, a porphyrin precursor, with these HT-1 associated neurologic crises, with elevated $\delta$-aminolevulinic acid excretion being a constant finding, and deficiency of RBC $\delta$-aminolevulinic acid hydratase activity being noted at the time of crisis.

These patients require close observation and require intravenous therapies for control of their pain, hypertension, and hyponatremia. Intravenous glucose inhibits the step prior to the hydratase ( $\delta$-aminolevulinic synthase) and is essential to begin the reversal of the HT-1 neurologic crisis. The use of intravenous $10 \%$ dextrose/normal saline solutions at 1.5 to 2 times the normal maintenance rate for age is the initial therapy, usually combined with rapid acting antihypertensives and analgesics. At times, intravenous boluses of $2 \%$ saline are required to treat recurring hyponatremia. Initiation (or reinitiation) of NTBC therapy is crucial to inhibit the production of SA at levels that are inhibiting the activity of $\delta$-aminolevulinic acid hydratase.

In a longitudinal study of HT-1 patients within the Quebec population, no patient developed an acute neurologic decompensation while compliant with NTBC therapy. ${ }^{32}$ This contrasted with an estimated hospital burden of $3.7 \%$ of the lives of non-NTBC-treated patients due to active neurological crises. We and others have observed neurologic crises in both infants and older children following short-term discontinuation of NTBC ( $>1$ month) without other overt signs of HT-1 disease (changes in AFP, liver function tests including PT/aPTT, phosphate, acidosis). ${ }^{82}$ This again highlights the importance of ongoing compliance and laboratory monitoring of plasma NTBC levels.

\section{Neuropsychology/neurobehavioral issues in HT-1}

Ten studies have reported on neuropsychological outcomes in HT-1 since the introduction of NTBC treatment. These studies raised the possibility that NTBC is associated with 
neuropsychological deficits that previously had not manifested in HT-1 patients. Complications attributed to NTBC treatment included low IQ and need for special education, ${ }^{50,83,84}$ cognitive decline, ${ }^{85}$ attention deficits, ${ }^{83,86}$ memory and processing problems, ${ }^{86}$ and psychomotor and behavioral impairment. ${ }^{9}$ Results from intelligence testing in individuals with HT-1 treated with NTBC appeared in only five studies; none were conducted in the United States and none included patients identified by NBS. IQ was reported in 41/177 (23\%) of cases described in the literature. Full-scale IQ ranged from 55 to 115. The mean Full-Scale IQ reported in 10 treated subjects from the Netherlands (ages 5-20 years) was $71,{ }^{85}$ almost 2 standard deviations below the population norm. In contrast, the 8 school-aged subjects from Poland performed as well as peers, with IQ scores within the expected range. ${ }^{86}$ Other studies reported mean IQ scores in the low average range. A more recent study suggested that IQ screening was not sufficient for cognitive monitoring and that executive function and social cognition, as well as IQ, are affected in HT-1 patients. ${ }^{87}$ The review of these studies confirms the importance of neuropsychological assessment as part of routine follow-up of patients with HT-1, and the need for further clinical research.

\section{Ophthalmologic considerations in HT-1}

High levels of tyrosine have been associated with corneal disease. The current hypothesis is that tyrosine crystalizes in corneal epithelial cells, disrupting their lysosomes and initiating an inflammatory response. ${ }^{88}$

Early signs and symptoms include lacrimation, photophobia, redness, and pain. On examination, there are central dendritic corneal erosions that stain poorly with fluorescein. Herpes simplex keratitis presents in a similar fashion and should be ruled out in the course of differential diagnosis. Early diagnosis and decreasing the blood tyrosine level through a low-phenylalanine and -tyrosine diet will improve and resolve the corneal disease. Ongoing observations of several patients cared for by our nominal group physicians, as well as those reported in our practitioner management survey, have noted photophobia associated with corneal crystals in HT-1 patients with reported blood tyrosine levels of $>700-$ $900 \mu \mathrm{mol} / \mathrm{L}$, easily reversed when the patients were placed under strict dietary control of tyrosine intake. This threshold level for presentation of keratitis is lower than previously reported. ${ }^{89-94}$

Patients with tyrosinemia type II usually develop severe corneal disease when plasma tyrosine levels are higher than $1000 \mu \mathrm{mol} / \mathrm{L}^{89}$ In contrast, individual cases of corneal pathology related to hypertyrosinemia have been reported in HT-1 patients on NTBC with plasma tyrosine levels ranging from 600 to $900 \mu \mathrm{M}$. However, average tyrosine levels preceding presentation are not always reported in these studies. ${ }^{91-93}$

An international NTBC study described 13 HT-1 patients with eye symptoms, one of whom developed corneal crystals that disappeared within a few days without withdrawal of the drug. ${ }^{95}$ Gissen et al. $^{90}$ reported the ophthalmologic outcomes of 11 patients treated with NTBC and low-protein diet for at least 2 years. Four patients were noncompliant with the diet. Among these, the highest plasma tyrosine concentration was $1410 \mu \mathrm{mol} / \mathrm{L}$ (the highest median: $900 \mu \mathrm{mol} / \mathrm{L}$ ). Nonetheless, even these patients had no ocular symptoms and all the ophthalmologic examinations were normal.

Most of these published papers are single-case reports and do not report long-term tyrosine levels. Some reported that elevated median tyrosine levels (as high as $900 \mu \mathrm{mol} / \mathrm{l}$ ) did not correlate directly with the presence of corneal crystals or with abnormal eye exams. ${ }^{90}$ Although the exact threshold is unclear, many metabolic centers aim to keep tyrosine levels $<600 \mu \mathrm{mol} / \mathrm{L}$ and our nominal group concurred (Table 3). Our practitioner management survey suggested that the majority of practitioners recommended annual ophthalmologic slit-lamp evaluations during the routine follow-up of their patients with HT-1. Our nominal group could not reach a clear consensus on performing an ophthalmologic slit-lamp exam annually; however, the exam should be done when a patient is symptomatic or at increased risk (Table 3).

\section{Cardiac considerations in HT-1}

Hypertrophic cardiomyopathy has been reported in patients with HT-1. ${ }^{74,96-99}$ Neither the mechanism nor the natural history of this complication is well understood. It could be due to inhibition of myocardial porphobilinogen synthase resulting in elevated levels of $\delta$-aminolevulinic acid, which can be cardiotoxic. The cardiac toxicity of hypertyrosinemia itself is unknown. Advanced liver disease causing increased cardiac output may also play a role in some cases. Since only a small fraction of untreated HT-1 patients develop cardiomyopathy, there must be other factors that determine individual susceptibility.

In most cases, diagnosis of cardiomyopathy was made by routine cardiac exams using echocardiograms and electrocardiograms or at autopsy. The above-referenced case reports and series demonstrated that patients did not have clinical symptoms related to cardiomyopathy, and that severe, progressive, and/or fatal cardiomyopathy is unlikely in HT-1 patients. ${ }^{74,96-99}$ Cardiomyopathy has been reported mostly in advanced cases with chronic liver disease as well as young infants with acute presentation. It may be a rare finding in early-diagnosed cases treated with NTBC. Echocardiogram findings are usually concentric biventricular hypertrophy and/ or interventricular septal hypertrophy. ${ }^{99}$

Cardiomyopathy resolves completely after initiation of NTBC treatment. ${ }^{98}$ In advanced cases diagnosed too late to benefit from NTBC treatment, cardiomyopathy apparently responded well to liver transplant. ${ }^{76}$

\section{Endocrine considerations in HT-1}

HT-1 patients, who are not treated with NTBC, can have pancreatic islet cell hyperplasia. Most patients are asymptomatic and it has been reported as a pathologic finding in autopsies. Patients with HT-1 may have episodes of 
hypoglycemia when they present with acute liver disease. Hypoglycemia could be caused by liver dysfunction or hyperinsulinism. ${ }^{100-102}$

\section{PREGNANCY AND HT-1}

Almost all the information about NTBC in pregnancy has come from animal studies (summarized by Vanclooster et al. $^{103}$ ). In the FAH knockout HT-1 mouse model by Grompe, NTBC administered to affected pregnant mothers does cross the placenta and there was no evidence for teratogenicity. ${ }^{104}$

There are three case reports in the medical literature of pregnancies in women with HT-1 treated with NTBC leading to the births of clinically healthy-appearing infants, although one did subsequently prove to have HT-1. No adverse effects on fetal development were reported in these three children. Tyrosine levels in these newborns ranged from 700 to $1157 \mu \mathrm{mol}$, with the levels in the HT-1 infant rising from 860 to $1248 \mu \mathrm{M}$ at 48 hours but in the other two children declining to normal levels when tested at 1 or 3 months. All three infants had no SA detected at birth (the pregnant mother of the HT-1 infant had been on NTBC throughout pregnancy). Urinary SA was noted in the HT-1 infant at 2 weeks of age. Development and general health of all three infants during the first year were reported as normal. ${ }^{103,105,106}$

If a patient with HT-1 becomes pregnant, FDA-approved NTBC (SOBI, Waltham, MA) prescribing information states "use during pregnancy only if the potential benefit justifies the potential risk to the fetus, and exercise caution when administering to a nursing woman." Given its pregnancy category $\mathrm{C}$ classification (due to insufficient available experience and data), our nominal physician group could not come to consensus regarding the use of NTBC during pregnancy (Nominal group: 22\% strongly agree; $44 \%$ agree; $11 \%$ neutral; $11 \%$ disagree; $11 \%$ strongly disagree). Reported consensus, however, for two related HT-1 pregnancy issues are outlined below.

\section{Recommendation $\mathbf{8 . 1}$}

Follow-up should be performed for infants born to women treated with NTBC during pregnancy (pregnancy category C medication). Nominal: $44 \%$ strongly agree; $56 \%$ agree. Evidence quality D.

\section{Recommendation $\mathbf{8 . 2}$}

Breastfeeding is contraindicated while the mother is being treated with NTBC. Nominal: 67\% strongly agree; 33\% agree. Evidence quality D.

\section{LONG-TERM CARE CONSIDERATIONS: NON- COMPLIANCE WITH PRESCRIBED TREATMENTS}

Nominal group members noted that early-treated HT-1 patients and their families have a range of different attitudes toward HT-1. A minority of patients and families find the continuous well-being of early-treated patients to be incongruent with medical recommendations for constant lifelong pharmacological and dietary therapy. This notion can be reinforced by the fact that brief periods of dietary or medicinal noncompliance are typically asymptomatic. In children and young adults, the authors have observed the occurrence of corneal crystals in several patients and also a paralytic neurological crisis requiring months of convalescence and rehabilitation therapy to regain mobility. Periods of noncompliance with high SA levels also carry the potential long-term risk of an increasing rate of somatic mutations in the liver that may promote the development of hepatocarcinoma. Most medical professionals consider that the biological effects of dietary and NTBC treatment are obvious and amply justify treatment recommendations.

Hence, it is important to know that noncompliance with diet or NTBC treatment is an emerging and easily-overlooked problem in some early-treated $\mathrm{HT}-1$ patients. The attitudes of families toward the treatment of HT-1 following the diagnosis of HT-1 by NBS are considered by the authors to be an important focus of research and surveillance.

\section{CONCLUSIONS}

It is evident from the evolving literature over the last decade that utilization of NTBC early in life results in substantial positive outcomes for patients with HT-1. Complications that were previously associated with $\mathrm{HT}-1$, including early infantile/childhood death, hepatic failure, painful, medically threatening neurologic crises, progressive renal dysfunction, hypophosphatemic rickets, and early development of HCC can be minimized or virtually eliminated if patients are started on NTBC by 1 month of age. This can only be accomplished by a robust NBS program, best achieved by screening neonatal blood for SA. It remains to be seen if the prevention of HCC persists during adult years. Similarly, the ongoing effects of the hypertyrosinemia produced by the use of NTBC, as well as any associated complications with its use, including long-term behavioral and neuropsychological effects, remain to be better understood. Nonetheless, the combination of NTBC and restricted dietary therapies as an approach to this once fatal pediatric disease remains a cause for optimism. It is hoped that the recommendations presented in this article will enable an even wider circle of medical professionals to approach this disease with confidence in providing an excellent medical outcome.

\section{SUPPLEMENTARY MATERIAL}

Supplementary material is linked to the online version of the paper at http://www.nature.com/gim

\section{ACKNOWLEDGMENTS}

Partial funding for this project has been provided to the Southeast Regional Newborn Screening and Genetics Collaborative (SERC) by the Health Resources and Services Administration (HRSA), grant H46MC24090, and by an unrestricted educational research grant obtained from SERGG (Southeastern Regional Genetics Group) via an unrestricted grant from Sobi, Inc. The authors are especially appreciative of the assistance of Elizabeth Dyke, who professionally facilitated our active discussions and assisted in all areas of the formatting and editing of this paper. We gratefully 
acknowledge the critical reading of this manuscript by Patrick McKiernan. We are thankful to all our patients and families for inspiring and teaching us every day about HT-1.

\section{DISCLOSURE}

All discussions of both the content and writing of the manuscript were performed without the presence or input of any representative of Sobi, Inc. J.M.C., R.S., C.F., M.G.C., M.G., G.M., and C.R.S. have participated as physician consultants/advisers intermittently for Sobi, Inc., the manufacturers of Orfadin (nitisinone) and have received compensation for their activities. The other authors declare no conflict of interest.

\section{REFERENCES}

1. Mitchell GA, Grompe M, Lambert M, Tanguay RM. Hypertyrosinemia. In: Valle D, Beaudet AL, Vogelstein B. et al. The Online Metabolic and Molecular Bases of Inherited Disease. New York, NY: McGraw-Hill; 2014. Available at: http://ommbid.mhmedical.com/content.aspx?bookid=971 \&sectionid=62673883.

2. Mitchell G, Larochelle J, Lambert $M$, et al. Neurologic crises in hereditary tyrosinemia. N Engl J Med. 1990;322:432-437.

3. Castilloux J, Laberge AM, Martin SR, Lallier M, Marchand V. "Silent" tyrosinemia presenting as hepatocellular carcinoma in a 10-year-old girl. J Pediatr Gastroenterol Nutr. 2007;44:375-377.

4. Weinberg AG, Mize CE, Worthen HG. The occurrence of hepatoma in the chronic form of hereditary tyrosinemia. J Pediatr. 1976;88:434-438.

5. van Spronsen FJ, Thomasse Y, Smit GP, et al. Hereditary tyrosinemia type I: a new clinical classification with difference in prognosis on dietary treatment. Hepatology. 1994;20:1187-1191.

6. Holme E, Lindstedt S. Nontransplant treatment of tyrosinemia. Clin Liver Dis 2000;4:805-814.

7. Schady DA, Roy A, Finegold MJ. Liver tumors in children with metabolic disorders. Transl Pediatr. 2015;4:290-303.

8. De Jesus VR, Adam BW, Mandel D, Cuthbert CD, Matern D. Succinylacetone as primary marker to detect tyrosinemia type I in newborns and its measurement by newborn screening programs. Mol Genet Metab 2014;113:67-75.

9. Mayorandan S, Meyer U, Gokcay G, et al. Cross-sectional study of 168 patients with hepatorenal tyrosinaemia and implications for clinical practice. Orphanet J Rare Dis 2014;9:107.

10. Schiff M, Broue P, Chabrol B, et al. Heterogeneity of follow-up procedures in French and Belgian patients with treated hereditary tyrosinemia type 1: Results of a questionnaire and proposed guidelines. J Inherit Metab Dis 2012;35:823-829.

11. de Laet C, Dionisi-Vici C, Leonard JV, et al. Recommendations for the management of tyrosinaemia type 1. Orphanet J Rare Dis 2013;8:8.

12. Singh RH, Rohr F, Frazier D, et al. Recommendations for the nutrition management of phenylalanine hydroxylase deficiency. Genet Med 2014;16:121-131.

13. Vockley J, Andersson HC, Antshel KM, et al. Phenylalanine hydroxylase deficiency: diagnosis and management guideline. Genet Med 2014;16: 188-200.

14. Waggoner J, Carline JD, Durning SJ. Is there a consensus on consensus methodology? Descriptions and recommendations for future consensus research. Acad Med. 2016;91:663-668.

15. Delbecq $A L$, Van de Ven AH, Gustafson DH. Group Techniques for Program Planning: A Guide to Nominal Group and Delphi Processes. Scott, Foresman: Glenview, IL, 1975.

16. Brouwers MC, Kho ME, Browman GP, et al. AGREE II: advancing guideline development, reporting and evaluation in health care. CMAJ. 2010;182:E839-842.

17. Vockley J, Chapman KA, Arnold GL. Development of clinical guidelines for inborn errors of metabolism: commentary. Mol Genet Metab 2013;108:203-205.

18. Maymone MB, Gan SD, Bigby M. Evaluating the strength of clinical recommendations in the medical literature: GRADE, SORT, and AGREE. J Invest Dermatol. 2014;134:e25.

19. Harbour R, Miller J. A new system for grading recommendations in evidence based guidelines. BMJ. 2001;323:334-336.
20. American Academy of Pediatrics Steering Committee on Quality I, Management. Classifying recommendations for clinical practice guidelines. Pediatrics 2004;114:874-877.

21. Lindblad B, Lindstedt S, Steen G. On the enzymic defects in hereditary tyrosinemia. Proc Natl Acad Sci USA 1977;74:4641-4645.

22. Lindstedt S, Holme E, Lock EA, Hjalmarson O, Strandvik B. Treatment of hereditary tyrosinaemia type I by inhibition of 4-hydroxyphenylpyruvate dioxygenase. Lancet 1992;340:813-817.

23. Knox WE, Edwards SW. Enzymes involved in conversion of tyrosine to acetoacetate. Methods Enzymol. 1955;2:287-300.

24. Grompe M. The pathophysiology and treatment of hereditary tyrosinemia type 1. Semin Liver Dis 2001;21:563-571.

25. La Du BN, Zannoni VG, Laster L, Seegmiller JE. The nature of the defect in tyrosine metabolism in alkaptonuria. J Biol Chem. 1958;230: 251-260.

26. Grompe $M$, al-Dhalimy $M$, Finegold $M$, et al. Loss of fumarylacetoacetate hydrolase is responsible for the neonatal hepatic dysfunction phenotype of lethal albino mice. Genes Dev. 1993;7(12A):2298-2307.

27. Rehak A, Selim MM, Yadav G. Richner-Hanhart syndrome (tyrosinaemiaII) (report of four cases without ocular involvement). $\mathrm{Br} J$ Dermatol 1981;104:469-475.

28. Bienfang DC, Kuwabara T, Pueschel SM. The Richner-Hanhart syndrome: report of a case with associated tyrosinemia. Arch Ophthalmol 1976;94: 1133-1137.

29. Endo F, Katoh H, Matsuda I. Putative genetic deficiency of 4-hydroxyphenylpyruvic acid dioxygenase in mice: a murine model for hereditary tyrosinaemia type III. J Inherit Metab Dis 1990;13:780-782.

30. Jorquera R, Tanguay RM. The mutagenicity of the tyrosine metabolite, fumarylacetoacetate, is enhanced by glutathione depletion. Biochem BiophysRes Commun 1997;232:42-48.

31. Ruppert S, Kelsey G, Schedl A, Schmid E, Thies E, Schütz G. Deficiency of an enzyme of tyrosine metabolism underlies altered gene expression in newborn liver of lethal albino mice. Genes Dev 1992;6:1430-1443.

32. Larochelle J, Alvarez F, Bussières JF, et al. Effect of nitisinone (NTBC) treatment on the clinical course of hepatorenal tyrosinemia in Québec. Mol Genet Metab 2012;107:49-54.

33. Watson M, Lloyd-Puryear M, Mann M, Rinaldo P, Howell R. Newborn Screening: toward a uniform screening panel and system. Genet Med 2006;8:1S-252S.

34. Grenier A, Lescault A, Laberge C, Gagne R, Mamer O. Detection of succinylacetone and the use of its measurement in mass screening for hereditary tyrosinemia. Clin Chim Acta. 1982;123:93-99.

35. Allard P, Grenier A, Korson MS, Zytkovicz TH. Newborn screening for hepatorenal tyrosinemia by tandem mass spectrometry: analysis of succinylacetone extracted from dried blood spots. Clin Biochem 2004;37: 1010-1015.

36. Schulze A, Frommhold D, Hoffmann GF, Mayatepek E. Spectrophotometric microassay for delta-aminolevulinate dehydratase in driedblood spots as confirmation for hereditary tyrosinemia type I. Clin Chem 2001;47:1424-1429.

37. Magera MJ, Gunawardena ND, Hahn SH, et al. Quantitative determination of succinylacetone in dried blood spots for newborn screening of tyrosinemia type I. Mol Genet Metab 2006;88:16-21.

38. Turgeon C, Magera MJ, Allard $P$, et al. Combined newborn screening for succinylacetone, amino acids, and acylcarnitines in dried blood spots. Clin Chem 2008;54:657-664.

39. Stinton C, Geppert J, Freeman K, et al. Newborn screening for tyrosinemia type 1 using succinylacetone-a systematic review of test accuracy. Orphanet J Rare Dis 2017;12:48.

40. Dimmock DP, Zhang Q, Dionisi-Vici C, et al. Clinical and molecular features of mitochondrial DNA depletion due to mutations in deoxyguanosine kinase. Hum Mutat 2008;29:330-331.

41. American College of Medical Genetics. Newborn Screening ACT Sheets and Confirmatory Algorithms. 2001. http://www.ncbi.nlm.nih. gov/books/NBK55827/. Accessed 29 June 2016.

42. Matern D, Tortorelli S, Oglesbee D, Gavrilov D, Rinaldo P. Reduction of the false-positive rate in newborn screening by implementation of MS/MS-based second-tier tests: the Mayo Clinic experience (2004-2007). J Inherit Metab Dis 2007;30:585-592.

43. Angileri F, Bergeron A, Morrow G, et al. Geographical and ethnic distribution of mutations of the fumarylacetoacetate hydrolase gene in hereditary tyrosinemia type 1. JIMD Rep 2015;19:43-58.

44. Grompe M, St-Louis M, Demers SI, al-Dhalimy M, Leclerc B, Tanguay RM. A single mutation of the fumarylacetoacetate hydrolase gene in French 
Canadians with hereditary tyrosinemia type I. N Engl J Med. 1994;331: 353-357.

45. Scriver CR. Human genetics: lessons from Quebec populations. Annu Rev Genomics Hum Genet. 2001;2:69-101.

46. Laberge AM, Michaud J, Richter A, et al. Population history and its impact on medical genetics in Quebec. Clin Genet. 2005;68:287-301.

47. Sniderman King L, Trahms C, Scott CR. Tyrosinemia type I. In: Pagon RA, Adam MP, Ardinger HH, et al. (eds). Gene Reviews: Seattle, WA, 1993.

48. Blackburn PR, Hickey RD, Nace RA, et al. Silent tyrosinemia type I without elevated tyrosine or succinylacetone associated with liver cirrhosis and hepatocellular carcinoma. Hum Mutat 2016;37:1097-1105.

49. Yang H, Al-Hertani W, Cyr D, et al. Hypersuccinylacetonaemia and normal liver function in maleylacetoacetate isomerase deficiency. J Med Genet. 2017;54:241-247.

50. Masurel-Paulet A, Poggi-Bach J, Rolland MO, et al. NTBC treatment in tyrosinaemia type I: long-term outcome in French patients. J Inherit Metab Dis 2008;31:81-87.

51. Bartlett DC, Lloyd C, MCKiernan PJ, Newsome PN. Early nitisinone treatment reduces the need for liver transplantation in children with tyrosinaemia type 1 and improves post-transplant renal function. $J$ Inherit Metab Dis 2014;37:745-752.

52. Schlune A, Thimm E, Herebian D, Spiekerkoetter U. Single dose NTBCtreatment of hereditary tyrosinemia type I. J Inherit Metab Dis 2012;35: 831-836.

53. Santra S, Baumann U. Experience of nitisinone for the pharmacological treatment of hereditary tyrosinaemia type 1. Expert Opin Pharmacother 2008;9:1229-1236.

54. CenterWatch. Orfadin (nitisinone). 2016. http://mww.centerwatch.com/ drug-information/fda-approved-drugs/drug/765/orfadin-nitisinone. Accessed 26 September 2016.

55. Lock EA, Ellis MK, Gaskin P, et al. From toxicological problem to therapeutic use: The discovery of the mode of action of 2-(2-nitro-4trifluoromethylbenzoyl)-1,3-cyclohexanedione (NTBC), its toxicology and development as a drug. J Inherit Metab Dis 1998;21:498-506.

56. El-Karaksy H, Rashed M, El-Sayed R, et al. Clinical practice: NTBC therapy for tyrosinemia type 1: How much is enough? Eur J Pediatr 2010;169: 689-693.

57. Neat JN, Wolff A, Kazmi $F$, et al. In vitro inhibition and induction of human liver cytochrome P450 enzymes by NTBC and its metabolism in human liver microsomes: Poster 146. Annual Meeting of International Society for the Study of Xenobiotics (ISSX), 2009.

58. Maiorana A, Malamisura M, Emma F, Boenzi S, Di Ciommo VM, Dionisi-Vici C. Early effect of NTBC on renal tubular dysfunction in hereditary tyrosinemia type 1. Mol Genet Metab 2014;113:188-193.

59. Sonneville K, Duggan C, Hendricks KM. Manual of Pediatric Nutrition, 5th edn. ed. People's Medical Publishing House-USA: Shelton, CT, 2014.

60. Rampini S, Vollmin JA, Bosshard HR, Muller M, Curtius HC. Aromatic acids in urine of healthy infants, persistent hyperphenylalaninemia, and phenylketonuria, before and after phenylalanine load. Pediatr Res. 1974;8:704-709.

61. Otten J, Hellwig J, Meyers L. Dietary Reference Intakes: The Essential Guide to Nutrient Requirements. National Academies Press: Washington, DC, 2006.

62. Acosta PB, Michals Matalon K. Nutrition management of patients with inherited disorders of aromatic amino acid metabolism in Nutrition Management of Patients With Inherited Metabolic Disorders. Jones and Bartlett: Sudbury, MA, 2010:119-174.

63. National Research Council (U.S.) Committee on Dietary Allowances. Recommended Dietary Allowances. Nabu Press: Washington, DC, 2012.

64. Lewis V, Rohr F, Van Calcar S. Protocol 3-Tyrosinemia Types $1 \mathrm{a}$ and $1 \mathrm{~b}$ Nutrition Support Protocols, 4th edn. Ross Products Division: Columbus, $\mathrm{OH}, 2001: 49-62$.

65. Daly A, Gokmen-Ozel H, MacDonald A, et al. Diurnal variation of phenylalanine concentrations in tyrosinaemia type 1: should we be concerned? J Hum Nutr Diet. 2012;25:111-116.

66. Wilson CJ, Van Wyk KG, Leonard JV, Clayton PT. Phenylalanine supplementation improves the phenylalanine profile in tyrosinaemia. J Inherit Metab Dis 2000;23:677-683.

67. Mayo Clinic. Test ID: PKU—Phenylalanine and Tyrosine, Plasma. 2016. http://www.mayomedicallaboratories.com/test-catalog/Clinical+ and + Interpretive/8380. Accessed 27 May 2016.

68. Bay A, Karaoglu O, Sivasli E, Leblebisatan G, Keskin M. An infant with prolonged circumcision bleeding and unexplained coagulopathy. Indian J Hematol Blood Transfus 2012;28:181-183.
69. Blohm ME, Vesterling-Horner D, Calaminus G, Gobel U. Alpha 1 -fetoprotein (AFP) reference values in infants up to 2 years of age. Pediatr Hematol Oncol. 1998;15:135-142.

70. Gale GB, O'Connor DM, Chu JY. Normal values of alpha-fetoprotein in neonates and infants. Pediatrics. 1988;82:138.

71. van Ginkel WG, Gouw AS, van der Jagt EJ, de Jong KP, Verkade HJ, van Spronsen FJ. Hepatocellular carcinoma in tyrosinemia type 1 without clear increase of AFP. Pediatrics. 2015;135:e749-752.

72. van Spronsen FJ, Bijleveld CM, van Maldegem BT, Wijburg FA. Hepatocellular carcinoma in hereditary tyrosinemia type I despite 2-(2 nitro-4-3 trifluoro- methylbenzoyl)-1, 3-cyclohexanedione treatment. J Pediatr Gastroenterol Nutr. 2005;40:90-93.

73. Zeybek AC, Kiykim E, Soyucen E, et al. Hereditary tyrosinemia type 1 in Turkey: twenty year single-center experience. Pediatr Int. 2015;57: 281-289.

74. Neto JS, Leite KMR, Porta A, et al. HCC prevalence and histopathological findings in liver explants of patients with hereditary tyrosinemia type 1. Pediatr Blood Cancer. 2014;61:1584-1589.

75. Dehghani SM, Haghighat M, Imanieh MH, Karamnejad H, Malekpour A. Clinical and para clinical findings in the children with tyrosinemia referring for liver transplantation. Int J Prev Med. 2013;4:1380-1385.

76. Mohan N, McKiernan P, Preece MA, et al. Indications and outcome of liver transplantation in tyrosinaemia type 1. Eur J Pediatr Supp/ 1999;158: S49-S54.

77. Paradis K. Tyrosinemia: the Quebec experience. Clin Invest Med 1996;19: 311-316.

78. Arnon R, Annunziato R, Miloh T, et al. Liver transplantation for hereditary tyrosinemia type I: analysis of the UNOS database. Pediatr Transplant 2011;15:400-405.

79. Bartlett DC, Preece MA, Holme E, Lloyd C, Newsome PN, McKiernan PJ. Plasma succinylacetone is persistently raised after liver transplantation in tyrosinaemia type 1. J Inherit Metab Dis 2013;36:15-20.

80. Forget S, Patriquin HB, Dubois J, et al. The kidney in children with tyrosinemia: sonographic, CT and biochemical findings. Pediatr Radiol. 1999;29:104-108.

81. Endo F, Sun MS. Tyrosinaemia type I and apoptosis of hepatocytes and renal tubular cells. J Inherit Metab Dis 2002;25:227-234.

82. Onenli Mungan N, Yildizdas D, Kor D, et al. Tyrosinemia type 1 and irreversible neurologic crisis after one month discontinuation of nitisone. Metab Brain Dis. 2016;31:1181-1183.

83. Thimm E, Herebian D, Assmann B, Klee D, Mayatepek E, Spiekerkoetter $U$. Increase of CSF tyrosine and impaired serotonin turnover in tyrosinemia type I. Mol Genet Metab 2011;102:122-125.

84. De Laet C, Munoz VT, Jaeken J, et al. Neuropsychological outcome of NTBC-treated patients with tyrosinaemia type 1. Dev Med Child Neurol 2011;53:962-964.

85. Bendadi F, de Koning TJ, Visser G, et al. Impaired cognitive functioning in patients with tyrosinemia type I receiving nitisinone. J Pediatr. 2014;164: 398-401.

86. Pohorecka M, Biernacka M, Jakubowska-Winecka A, et al. Behavioral and intellectual functioning in patients with tyrosinemia type I. Endokrynol Diabetol Chor Przemiany Materii Wieku Rozw 2012;18:96-100.

87. van Ginkel WG, Jahja R, Huijbregts SC, et al. Neurocognitive outcome in tyrosinemia type 1 patients compared to healthy controls. Orphanet J Rare Dis 2016;11:87.

88. Michalski A, Leonard JV, Taylor DS. The eye and inherited metabolic disease: a review. J $R$ Soc Med. 1988;81:286-290.

89. Tsai CP, Lin PY, Lee NC, Niu DM, Lee SM, Hsu WM. Corneal lesion as the initial manifestation of tyrosinemia type II. J Chin Med Assoc. 2006;69: 286-288.

90. Gissen P, McKiernan PJ, Preece MA, Wilshaw HA. Ophthalmic follow up in patients with tyrosinaemia type 1 on on NTBC. J Inherit Metab Dis. 2001;24(Supplement 1):32.

91. Ahmad S, Teckman JH, Lueder GT. Corneal opacities associated with NTBC treatment. Am J Ophthalmol. 2002;134:266-268.

92. Schauwvlieghe PP, Jaeken J, Kestelyn P, Claerhout I. Confocal microscopy of corneal crystals in a patient with hereditary tyrosinemia type I, treated with NTBC. Cornea. 2013;32:91-94.

93. Wisse RP, Wittebol-Post D, Visser G, van der Lelij A. Corneal depositions in tyrosinaemia type I during treatment with Nitisinone. BMJ Case Rep 2012;2012.

94. Gissen P, Preece MA, Willshaw HA, McKiernan PJ. Ophthalmic follow-up of patients with tyrosinaemia type I on NTBC. J Inherit Metab Dis 2003;26:13-16. 


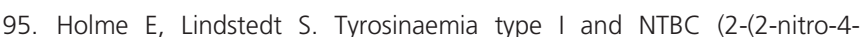
trifluoromethylbenzoyl)-1,3-cyclohexanedione). J Inherit Metab Dis 1998; 21:507-517.

96. Lindblad B, Fällström SP, Höyer S, Nordborg C, Solymar L, Velander H. Cardiomyopathy in fumarylacetoacetase deficiency (hereditary tyrosinaemia): a new feature of the disease. J Inherit Metab Dis 1987;10:319-322.

97. Arora N, Stumper O, Wright J, Kelly DA, McKiernan PJ. Cardiomyopathy in tyrosinaemia type I is common but usually benign. J Inherit Metab Dis 2006;29:54-57.

98. Andre N, Roquelaure B, Jubin V, Ovaert C. Successful treatment of severe cardiomyopathy with NTBC in a child with tyrosinaemia type I. J Inherit Metab Dis 2005;28:103-106.

99. Mohamed S, Kambal MA, Al Jurayyan NA, et al. Tyrosinemia type 1: a rare and forgotten cause of reversible hypertrophic cardiomyopathy in infancy. BMC Res Notes. 2013;6:362.

100. Perry TL. Tyrosinemia associated with hypermethioninemia and islet cell hyperplasia. Can Med Assoc J. 1967;97:1067-1075.

101. Carson NA, Biggart JD, Bittles AH, Donovan D. Hereditary tyrosinaemia. Clinical, enzymatic, and pathological study of an infant with the acute form of the disease. Arch Dis Child. 1976;51:106-113.

102. Russo P, O'Regan S. Visceral pathology of hereditary tyrosinemia type I. Am J Hum Genet. 1990;47:317-324.

103. Vanclooster A, Devlieger R, Meersseman W, et al. Pregnancy during nitisinone treatment for tyrosinaemia type I: first human experience. JIMD Rep 2012;5:27-33.
104. Grompe M, Overturf K, al-Dhalimy M, Finegold M. Therapeutic trials in the murine model of hereditary tyrosinaemia type I: a progress report. J Inherit Metab Dis 1998;21:518-531.

105. Garcia Segarra N, Roche S, Imbard A, et al. Maternal and fetal tyrosinemia type I. J Inherit Metab Dis 2010;33 Suppl 3:S507-510.

106. Kassel R, Sprietsma L, Rudnick DA. Pregnancy in an NTBC-treated patient with hereditary tyrosinemia type I. J Pediatr Gastroenterol Nutr 2015;60:e5-e7.

(c) (1) $(9)$ This work is licensed under a Creative Commons Attribution-NonCommercial-NoDerivs 4.0 International License. The images or other third party material in this article are included in the article's Creative Commons license, unless indicated otherwise in the credit line; if the material is not included under the Creative Commons license, users will need to obtain permission from the license holder to reproduce the material. To view a copy of this license, visit http://creativecommons.org/licenses/ by-nc-nd/4.0/

(C) The Author(s) 2017 